\title{
The Role of Religious Institutions, Electronic Games, Books, and Educational Stories in the Development of the Child's Culture from the Perspective of Jordanian Mothers According to Some Variables
}

\author{
Rima Al Harbat ${ }^{1} \&$ Khalaf Al Saqarat $^{2}$ \\ ${ }^{1}$ Isra University, Jordan \\ ${ }^{2}$ Mutah University, Jordan \\ Correspondence: Rima Al Harbat, Isra University, Jordan.
}

Received: December 15, 2016

doi:10.5539/ies.v10n4p141
Accepted: February 19, $2017 \quad$ Online Published: March 30, 2017

URL: https://doi.org/10.5539/ies.v10n4p141

\begin{abstract}
The purpose of this study is to investigate the role of religious institutions, electronic games, books and educational stories in the development of the child's culture from the perspective of some of Jordanian mothers in Al Karak Governorate, and to achieve the objective of the study a questionnaire was build, it consisted of (33) items divided into (3) dimensions. The study sample consisted of 175 mothers; "Kruskal Walls test" was used to know the significance of differences in the responses of the study sample. The study reached some results, most notably a good impact of electronic games on the culture of the child with a mean of (2.76) this came in the first rank, in the second rank came the impact books and educational stories, with a mean of (2.61) the impact of religious institutions (houses of worship) was in third rank with a mean of (2.32).

Results also show a statistically significant differences at the significance level $(\alpha=0.05)$ in the views of mothers due to the educational level of the mother and in favor of (university and above), and there was also a positive role for books and educational stories attributed to the higher level of education, there were also no statistically significant differences at the significance level $(\alpha=0.05)$ in the views of mothers attributed the economic level of the family.
\end{abstract}

Keywords: role of religious institutions, electronic games, books and educational stories, child's culture

\section{Introduction}

Every society has its own characteristics and advantages that distinguish it from other societies and cultures, which in turn one way or another affect the behavior of all aspects of life and all communities seek to make their members more adaptive and constant with the community in which they live, whether in the organized habits and acquaintances and perceptions and his beliefs and his lifestyle and required education to suit with the beliefs and customs of the surrounding community, as is the scientific and economic level of the communities and the living situation is considered a source of such differences in light of scientific and technological enormous revolution, though the family is still the most important of these institutions essential foundation which thrives where the child arises, through which he receives his knowledge and information and cultures, it allows various influences of society and even the degree of impact and depth in his behavior (Kanaan, 2014).

As to what it means that the culture of socialization occupies an important place during the childhood years up to the age of maturity. During these critical years are the basic characteristics of social affiliation process, and self-identity, which a different social environment with its variants and forms and means play a crucial role in it. And culture is beyond identity to the personal composition as a whole and determine the behavior and orientation, through the processes of growth experienced by the child and in various emotional and cognitive, social and behavioral dimensions, and the Arab culture of the child should not be seen as a process to improve the intellectual and refinement of the senses only, but more importantly is the setting for the future Orient-free malpractice facing communities, and through the development of future generations.

\subsection{The Problem of the Study}

The researchers noted a clear disparity in knowledge and cultural, scientific and social information in children by virtue of their work in the follow-up field and supervision of that age group, prompting their attempt to 
investigate the role of religious institutions (houses of worship), electronic games, books and educational stories in child's culture development from the viewpoint of Jordanian mothers. The family contribution in the culture of the child based and is an active and influential way on some dimensions, whether educational or economic of the families, so the study problem centered in answering the following question: the role of religious institutions (houses of worship), electronic games, books and educational stories in developing the child's culture from the viewpoint of Jordanian mothers depending on the variables of educational and economic level of the mother?

\subsection{Significance of the Study}

It is no secret the high impact of social and family upbringing and the extent of providing the necessary care in the development of cultural storage of the child and the development of his mind and knowledge and by providing all the necessary services needed for children that encouraged cultural and knowledge heritage he has, as the importance of this study came through what its results can come up with in providing advice and guidance for those involved in the development of the culture of the child as a societal responsibility primarily and an essential duty for those in charge of education in particular.

\subsection{The Purpose of the Study}

1) To identify the role of religious institutions, electronic games, books and educational stories in the development of children's culture from the perspective of Jordanian mothers.

2) To identify the impact of the educational level of the mother variable in the development of children's culture in Karak governorate.

3) To identify the impact of the economic level of the mother variable in the development of children's culture in Karak governorate.

\subsection{Questions of the Study}

1) What is the role of religious institutions and electronic games in the development of children's culture from the perspective of Jordanian mothers?

2) Is there a statistically significant difference at the level of significance $(\alpha=0.05)$ in the role of mothers in the development of child's culture, according to the variable of educational level of the mother?

3) Is there a statistically significant difference at the level of significance $(0.05 \leq \alpha)$ in the role of mothers in the development of child's culture according to a changing economic level of the mother?

\subsection{Determinants of the Study}

Temporal determinants: the academic year 2016-2017

Spatial determinants: Schools at Al Karak governorate.

Objective determinants: the role of religious institutions, electronic games, books and stories in the educational development of the child's culture from the point of view of Jordanian mothers according to some variables.

\section{Review of Related Literature}

Many studies were conducted that focused on the development of the culture of the child and the need for attention to this critical stage and the great role played by families represented by the role of the mother who is well known as being the first bowl where the child draws his information and knowledge from.

Rabije (2006) conducted a study aimed to investigate the role of fathers in their children's education within the intact family environment that focused on the overall development of their children and the need to give children a range of experiences, regardless of family environments that qualifies them for life and offer a range of appropriate educational activities focused on some aspects of health and physical health and education with concentration on the development of their personalities through several dimensions.

Happiness in achievement in order to achieve the best, urged children to education and achievement and work, and the educational level of the parents has a significant impact on the level of culture and Academic achievement of their children and get good results in school tests without neglecting the role of psychological development through the availability of feelings of love and care, the mother also has a crucial role in the development of individual identity in order to ensure independence in the growth, education, and scientific and intellectual progress as well as emotional progress, the study also demonstrated the significant role of the father relating the functional development inside the house with a focus on doing works with the participation of children in cooperation with the mother which makes children more eager to do things better in the future.

Usa (2009) also mentioned in his study which was conducted among students from various ethnic backgrounds 
about the great effect done by parents, teachers, peers on the development of culture of the child and his integration in education in various educational stages and that was clear by measuring the degree of compliance with the orders provided by the school and the positive academic behaviors, and participating in extra-curricular activities and limitations provided by the school for the fun and merge and build mutual trust with them and selfmotives for education and changes in performance on tests of cognitive and academic skills. The results also indicate low levels of school discipline for black students compared to whites, and pointed out that the black students had to have high levels of self-esteem, he also pointed that the social support for the mother is linked positively with all the indicators also the peer support has significant impact on the education that we want. The teacher's role and his continued support have a significant impact in slowing and the alleviation of non-compliance with the instructions and school rules and participation in extra-curricular activities, and it also pointed to the influence of family background and parental education on the child's culture and his education and the presence of gaps between students of the same low income families.

And the results also indicated that students from high economic and social income families tend to deal with academic challenges, with a greater sense of internal control towards the success than the students of low-income. The report pointed to the obvious impact of the participation of the families with their children in education and family culture in which a child grow up, it has a role in shaping the academic mentality of the child in terms of reading and conversation with them and working to motivate them towards the accomplishment and achievement, perseverance and discovery, the family expectations about the children played a major role in raising achievement motivation among children.

The aim of Cowan (1999) study is to investigate the impact of parental participation in children's education and in creating and building a strong positive family and it investigated the schools' and the community's in which the child lives observations and the relationship between them in the city of Newfoundland where it relied on the observations and the response of teachers and the community and the relationship between the school and the community and the involvement of parents in the activities and to highlight the knowledge and theories of parental benefits and draw up a list to help schools in the re-education reform and the restructuring and development of parity among students and encourage parents to partnership. And it confirmed that when parents show a large and strong interest in the education of their children, that enhance the spirit of development and that the lack of attention is a key of negative that discouraging and preventing the achievement of the desired goals. The provision of an appropriate environment allows families access to basic education requirements. And the role of the involvement of parents in the formal education of the children improves the performance of their children.

The participation must be more effective and inclusion in the long term and planned well to bear its fruit. It also showed that the benefits are not limited to early childhood and elementary stage, but continue to secondary school. It showed that the involvement of parents in the home-education of their children is not enough to ensure the quality of schools as institutions serving the local community. And that child with low incomes must be involved and help their parents to get a good education. It also showed that the school and the home shouldn't be looked at in isolation from each other but are linked with the entire world.

The researcher pointed to the multiple ways through which assistance is provided by the parents of children through: child participation of his hobbies and any information related to this, to talk about the important professions in life ,, to participate and share knowledge with teachers and other school students in reading and math, help the child to coach athletics team, putting instructions for brief newsletter, he also pointed out that parents are the most important episode because members of the community every day faced with many complex issues and the parents possess the skills to meet these challenges and the opposite of that there will be disorder and disturbance in the personality of students lead ultimately to failure to achieve the desired education that we want.

Usher (2012) pointed out in his report entitled main roles assigned to parents and to be followed to ensure the education of their children a proper education and if the culture of parents play an essential role in education. The educational level of parents and income and overlook the behaviors of students has a large impact in the educational attainment of students and raise their motivation toward learning, education and school success, as an impact of the role of parental beliefs and participation in education at the school achievement and excellence has emerged. The study recommended the need to establish clear and consistent rules about homework, watching TV, extracurricular activities outside the school and its role in strengthening the schooling process and encourage students to research, exploration and development of the spirit of creativity and develop the talents of children in general. The report also pointed out that the beliefs of the parents has a large clear role in increasing motivation towards the education of children and parents who have high expectations about the efficiently of their children 
and are encouraged on an ongoing basis to solve their problems have a major impact in increasing the motivation to learn on the contrary of controlling parents who use punishment method.

Mutairi (2011) also noted to the great role of the family in education and the role of the media and can be summarized as follows: Understanding the role of media in shaping the future of our children and their education, and the positive role in developing critical question skills in children, and use the conscious media technology by providing useful news. The researcher suggested that parents should: encourage their children to the conscious choice of programs that they follow, and the participation of children of what they see or hear, or read, the optimal use of these means in terms of handling and allotted time and adopting alternative activities for the modern scattered media.

\subsection{Comments on Previous Studies and the Location of the Current Study}

We note through a review of previous studies, that it focused on the role of the family in the overall development to encourage and stimulate children's interest in science and success and to seek knowledge and information wherever existed and distinguish between beneficial and harmful ones. The current study also tried to monitor and follow up the impact of the educational level of the mother on the development of a culture of their children. The US Education report in 2009 focused on the mother role of social support for integration with the school and its positive impact, the present study has also tried to monitor the mother's guidance and follow-up to the impact of religious institutions and libraries as a source for the development of cultural identity in general, as the current study attempts to identify the impact of family income and education level of the mother on the development of cultural level of the children. Al-Mutairi (2010) was the only one in focusing on the role of the family to deal with the media and its basic role of guiding their children in order to make an influential media positively in the lives of children through monitoring and guidance and allocate times for follow-up by the children to the media, and in general the current study was not confined to talk about the role of mother in teaching children but her role in the growth of their culture and the wider general concept through guidance to her children. The current study differed from previous studies in monitoring the role of specific effects such as (houses of worship, books and educational stories and electronic games).

\section{Procedures of the Study}

\subsection{Building the Study Tool}

- The researchers reviewed the literature related to the children's culture, in order to design items and paragraphs of the questionnaire according to the three dimensions of the study, namely, (the role of religious institutions (houses of worship), the role of electronic games, the role of educational books and stories).

- Then the validity and reliability of the items of the questionnaire were verified through submitting it to specialized arbitrators.

- The items that don't belong to the domain and are not agreed upon from the jury were isolated.

- The researchers reached the final version of the tool according to its dimensions and in each dimension there are (11) items, with a total of (33) items on all dimensions, which included most of the daily activities and practices for all families in our community towards their children.

\subsubsection{The Tool Validity}

The validity of the tool was verified through submitting it in its primary form to (9) arbitrators with experience and competence from the faculty members at Mutah University, and Isra University and they were asked to express their views on the items of the tool in terms of language and clarity of items and appropriateness of each item for the domain that it belongs to, as well as making any suggestion or amendment to those items and in the light of the notes of the arbitrators some of the items have been modified to reformulate and deleting some of them until it becomes in its current final form.

\subsubsection{Internal Consistency}

The tool has been applied to the 30 mothers from outside the study sample and from the same study population then Pearson correlation coefficient was calculated between the tool and the item on the domain which it belongs to and the following table shows that. 
Table 1. Pearson correlation coefficient between the tool and the paragraph

\begin{tabular}{lccccc}
\hline Paragraph No. & Correlation coefficient & Paragraph No. & Correlation coefficient & Paragraph No. & Correlation coefficient \\
\hline 1 & $* * 0.53$ & 12 & $* * 0.46$ & 23 & $* * 0.57$ \\
2 & $* * 0.61$ & 13 & $* * 0.73$ & 24 & $* * 0.49$ \\
3 & $* * 0.43$ & 14 & $* * 0.51$ & 25 & $* * 0.41$ \\
4 & $* * 0.52$ & 15 & $* * 0.43$ & 26 & $* * 0.70$ \\
5 & $* * 0.71$ & 16 & $* * 0.67$ & 27 & $* * 0.49$ \\
6 & $* * 0.79$ & 17 & $* * 0.58$ & 28 & $* * 0.48$ \\
7 & $* * 0.61$ & 18 & $* * 0.63$ & 29 & $* * 0.59$ \\
8 & $* * 0.45$ & 19 & $* * 0.44$ & 30 & $* * 0.71$ \\
9 & $* * 0.81$ & 20 & $* * 0.66$ & 31 & $* * 0.58$ \\
10 & $* * 0.66$ & 21 & $* * 0.47$ & 32 & $* * 0.70$ \\
11 & $* * 0.47$ & 22 & $* * 0.71$ & 33 & $* 0.66$ \\
\hline
\end{tabular}

*Correlation coefficients between the tool and the item and the domain which it belongs to.

By reviewing the previous table it is clear that all correlation coefficients were positive and statistically significant at the significance level $(\alpha=0.001)$ and this shows that every paragraph in the field measures the same domain it belongs to.

\subsubsection{Reliability}

The tool has been applied to the 30 mothers from the study population and outside its sample, the reliability coefficient was calculated using the Cronbach's alpha and the following table shows the results.

Table 2. Reliability coefficient

\begin{tabular}{cc}
\hline Domain & Reliability coefficient \\
\hline The role of religious institutions & 0.882 \\
The role of electronic games & 0.843 \\
The role of books and stories & 0.876 \\
Total & 0.885 \\
\hline
\end{tabular}

By reviewing the previous table it can be noted that the values of reliability coefficients were high and appropriate for the purposes of this study.

\subsubsection{Study Approach}

The study followed the descriptive analysis approach as this approach examines variables as it exists in its natural case to determine the relationships that can occur between these variables. The search through the questionnaire stop at the role of religious institutions (places of worship) and books and electronic games in the development of the child's culture from the point of view of mothers, according to the variables of the economic level and the degree of the mother's education.

\subsection{The Study Sample}

After reviewing the directory of educational statistics by Al Karak Directorate of Education, The basic schools has been limited and a random sample was taken from all the districts in the province. A questionnaire was distributed to the students and they were asked to send it to mothers in order to answer them, the researchers talked with them by telephone to clarify the aim of the questionnaire and that the responses will be treated confidentially and it is for the purposes of scientific research only.

\subsection{Statistical Methods}

The statistical package (SPSS) was used to unload data for calculating the means of mothers' answers according to triple Likert scale depending on the variables of the study (the economic level, the education of the mother) and the significance of the differences in these responses using Kruskal-Walls, and the equation of Cronbach Alpha for internal consistency, and Spearman to calculate the repeated reliability.

\section{Results of the Study and Its Discussion}

This section includes a presentation of the results that the study has been reached by answering its questions and 
testing its hypotheses, as follows:

The researchers indicate that the use of the following ranking to denote the averages of respondents' responses on the degree of approval and the following table illustrates this.

Table 3. Interpretation of semantics of sample response averages

\begin{tabular}{cc}
\hline Degree of approval & Mean \\
\hline Weak & From 1-1.99 \\
Moderate & From 2-2.99 \\
Large & From 3-4 \\
\hline
\end{tabular}

\subsection{Results Related To the First Question}

What is the role of religious institutions, electronic games, books and educational stories in the development of children's culture from the perspective of Jordanian mothers?

To answer this question means and standard deviations for the respondents' approval grades on statements relating to the role of religious institutions in the development of the culture of the child from the point of Jordanian mothers were calculated, and the results were as follows:

Table 4. Means, standard deviations, and the rank for the degree of respondents' agreement on the study domains as a whole

\begin{tabular}{lccc}
\hline Domain & Mean & Standard deviation & Rank \\
\hline Role of religious institutions & 2.32 & 0.262 & 3 \\
\hline Role of electronic games & 2.76 & 0.270 & 1 \\
\hline Role of books and educational stories & 2.61 & 0.147 & 2 \\
\hline
\end{tabular}

Through a review of the previous table, it is noted that all the domains were all moderately in its impact on the culture of the child and acquaintances with regard to the role of electronic games in the development of the child's culture came first with a mean of (2.76) with a moderate level but it is high and the reason for this is because the electronic games occupies a long time in the lives of our children and spend long periods in practicing and watching it whether it is indoors or outdoors by the widespread and available devices for many children such as iPad or cellular devices which are also available in the markets cheaply so we see that many of the children are keen to use the amusement and recreation or for the development of knowledge and information, which, unfortunately, may amount to addiction when others in practicing it for long periods and thus influenced their behaviors, knowledge and culture one way or another, as indicated by Selnow (1984) in her study.

As the domain relating the role of books and educational stories occupied the second place with a mean of (2.61) and we note the moderate impact of the role of stories and educational books, but is rather high as some families try to struggle to provide everything that would increase the repertoire of their children cognitive and cultural in several ways, including books and stories and educational brochures that fit with their orientation, age and preferences and desires and are attracting their attention is also seeking to participate in the reading in a meaningful, targeted and intent to provide knowledge and information to suit the habits and traditions of the society in which we live but that was moderately as shown, and the cause of middle outcome may be attributed to that families are permanently busy in work outside the home whether father or mother and the large size of families in some Jordanian families modest economic situation that makes families concerned and larger in securing the basic needs of food and drink more than their interest in providing educational books and stories for children, the reason is also due to the large duties and requirements of school children thus preventing the spread of reading books and educational stories better but we do not deny the existence of interest in that but is fairly modest.

The third domain relating the role of religious institutions (houses of worship) ranked third with a moderate degree in its contribution to the development of culture of the child and acquaintances, there is no doubt that there are shortcomings by the religious institutions in the provision of knowledge and information towards our children and this is what has been observed by the results of this study, where it got less arithmetic means by (2.32) the reason may be attributed to the lack of a clear vision about the needs of our children from cultural information and knowledge by those in charge of those religious institutions and being able to live in this society 
in peace and security and enable it to confront problems that can beset him and his life and his future. The reason is also due to the absence of a clear philosophy set concerted institutions involved in efforts to bring up the child and sponsorship, whether family or social institutions or educational help to build and develop future plans for what should avail itself the child of knowledge and information characterized by transparency in in presenting it and accountable in the event of default.

The results will be displayed in detail for each domain separately as indicated in the following Table 5 .

Table 5. Means, standard deviations, and rank for degree of respondents' approval on the statements relating to the role of religious institutions in the development of the child's culture from the point of Jordanian mothers

\begin{tabular}{|c|c|c|c|c|}
\hline N. Items & Mean & Standard deviation & Degree of approval & Rank \\
\hline 4 Help him to earn appropriate social and cultural habits. & 3.46 & 0.533 & Large & 1 \\
\hline 3 Help him to expand his own perceptions & 3.28 & 0.499 & Large & 2 \\
\hline 1 My child going to houses of worship develops his language & 3.26 & 0.606 & Large & 3 \\
\hline 2 It helps him earn more knowledge. & 3.14 & 0.488 & Large & 4 \\
\hline 5 It helps him earn multiple moral values. & 3.11 & 0.582 & Large & 5 \\
\hline 9 It encourage my child to ask for more knowledge & 3.01 & 0.597 & Large & 6 \\
\hline 8 It contributes to the development of innovation. & 2.62 & 0.778 & Moderate & 7 \\
\hline 11 It Urges him and encourages him to ask for more knowledge. & 2.35 & 0.795 & Moderate & 8 \\
\hline 7 It helps him develop his initiatives. & 2.18 & 0.788 & Moderate & 9 \\
\hline 10 It helps him talk about the different activities of these institutions & 2.05 & 0.905 & Moderate & 10 \\
\hline 6 It makes him more adaptable to society. & 1.91 & 0.772 & Low & 11 \\
\hline Total & 2.32 & 0.262 & Moderate & \\
\hline
\end{tabular}

The previous table shows the means and standard deviations for the respondents' approval grades on statements relating to the role of religious institutions in the development of culture of the child from the viewpoint of Jordanian mothers in descending order, the items number $(4.3,1.2,5)$ got a large approval grades of the content of the items, item number (4) was the highest (religious institutions help to give adequate social and cultural habits) and it received the highest arithmetic mean (3.46), while the items $(8.11,7.10)$ got a medium-approval grades, while item (6) (make it more adapted to combined) got the lowest mean (1.91) and a low approval grade.

The table shows that the total items got the mean (2.32) and a medium degree of approval, and this indicates that the role of religious institutions in the development of the child's culture from the point of Jordanian mothers was moderate.

This may be attributed to the lack of clarity of the concept of culture in the minds of mothers and the presence of other more attractive and suspense upbringing institutions affect the child's culture, as it may be attributable to the poor role played by those in charge of these institutions to attract the age group of coaxing and encouragement to join these institutions and to the weakness of those who are in charge of the development of a clear and well thought out long-term plans.

Results regarding the role of gaming in the development of the child's culture from the point of Jordanian mothers?

To answer this question the arithmetic means and standard deviations for the grades approval of the sample were calculated on phrases relating to the role of electronic games in the development of child's culture from the point of Jordanian mothers, and the results were as follows:

Table 6. Means, standard deviations, and the arrangement for respondents' approval degree on the statements regarding the role of electronic games in the development of child's culture from the point of Jordanian mothers

\begin{tabular}{|c|c|c|c|c|c|}
\hline N. & Items & Mean & $\begin{array}{l}\text { Standard } \\
\text { deviation }\end{array}$ & $\begin{array}{l}\text { Degree of } \\
\text { approval }\end{array}$ & Rank \\
\hline 2 & I try to choose the appropriate electronic games for my child's capabilities. & 3.51 & 0.513 & Large & 1 \\
\hline 3 & $\begin{array}{l}\text { I am trying to choose the electronic games that fit our cultural, religious and social } \\
\text { environment }\end{array}$ & 3.42 & 0.517 & Large & 2 \\
\hline
\end{tabular}




\begin{tabular}{|c|c|c|c|c|c|}
\hline 8 & The selected games develop the knowledge of my child. & 2.97 & 0.754 & Moderate & 3 \\
\hline 11 & It develops my child's science fiction. & 2.33 & 0.991 & Moderate & 4 \\
\hline 9 & Selected games help my child to keep up with scientific and cultural developments & 2.11 & 0.909 & Moderate & 5 \\
\hline 1 & $\begin{array}{l}\text { I am trying to acquire electronic games to keep pace with technological and } \\
\text { scientific progress. }\end{array}$ & 2.01 & 0.657 & Moderate & 6 \\
\hline 5 & I share my child in playing these games & 1.87 & 0.907 & Low & 7 \\
\hline 7 & I scan these games before I buy it and I choose the right ones. & 1.87 & 0.932 & Low & 8 \\
\hline 10 & It developments his language skills clearly. & 1.86 & 0.822 & Low & 9 \\
\hline 4 & I set a specific time for the using electronic games & 1.83 & 0.582 & Low & 10 \\
\hline 6 & I leave the freedom for my child to choose the games alone. & 1.69 & 0.586 & Low & 11 \\
\hline & Total & 2.76 & 0.270 & Moderate & \\
\hline
\end{tabular}

Table 5 shows the arithmetic means and standard deviations for the grades of respondents approval on statements regarding the role of electronic games in the development of child's culture from the point of Jordanian mothers in descending order, where item No. 2 got a mean of (3.51) and a large degree of approval, it was the highest and stated that (I'm trying to choose the right electronic games for my child's capabilities), while item No. (6) got the degree of a few approval, which stated that ( I leave freedom for my child to choose the games alone) lit got the lowest mean of (1.69).

The reason may be due to the keenness of mothers to direct intervention in the selection of what is useful for the child according to his age and mental level, commensurate with the religion, customs and traditions of the society, mothers also try some non-hazardous games to the life of their child, according to his age level, especially since most of the games available in the markets have been designed outside our communities.

The reason in the selection of the mothers of the games is also due to its multiple disadvantages especially during the students' time at the school where the child spends a lot of time in practicing those games which require intervention by the mothers to choose the type and time of the exercise of those games especially that most of the goals are not a tutorial.

Results relating the role of books and stories in the development of child's culture from the point of Jordanian mothers

To answer this question the arithmetic means and standard deviations for the sample approval of grades are calculated on items relating to the role of books and stories in the development of the culture of the child from the point of Jordanian mothers, and the results were as follows

Table 7. Means, standard deviations, and the rank of respondents' approval degree on the statements regarding the role of books and stories in child's cultural development from the point of Jordanian mothers

\begin{tabular}{|c|c|c|c|c|c|}
\hline $\mathrm{N}$ & Items & Mean & $\begin{array}{l}\text { Standard } \\
\text { deviation }\end{array}$ & $\begin{array}{l}\text { Degree of } \\
\text { approval }\end{array}$ & Rank \\
\hline 11 & $\begin{array}{l}\text { I present the appropriate reinforcement for my child when he reads books and } \\
\text { educational stories. }\end{array}$ & 3.38 & 0.563 & Large & 1 \\
\hline 10 & $\begin{array}{l}\text { I follow my child's school activities that are related to the free reading in } \\
\text { coordination with the teacher }\end{array}$ & 3.20 & 0.703 & Large & 2 \\
\hline 6 & selected books and stories expand his perception & 3.04 & 0.673 & Large & 3 \\
\hline 7 & I help my child to choose what suits him from books and stories & 3.00 & 0.871 & Large & 4 \\
\hline 2 & I constantly encourage my child to read & 2.97 & 0.906 & Moderate & 5 \\
\hline 9 & I encourage him to devote time regularly to read and free reading & 2.93 & 0.788 & Moderate & 6 \\
\hline 8 & I constantly follow what my child read so as not to forget & 2.80 & 0.837 & Moderate & 7 \\
\hline 1 & $\begin{array}{l}\text { I often seek for the acquisition of books and stories and a variety of magazines for } \\
\text { my child }\end{array}$ & 2.51 & 1.005 & Moderate & 8 \\
\hline 3 & I share my child in reading varied stories and books & 2.27 & 0.960 & Moderate & 9 \\
\hline 4 & The selected books and stories develop the vocabulary he has & 2.26 & 0.914 & Moderate & 10 \\
\hline \multirow[t]{2}{*}{5} & It develops his scientific and cognitive imagination. & 2.05 & 0.921 & Moderate & 11 \\
\hline & Total & 2.61 & 0.147 & Moderate & \\
\hline
\end{tabular}

As shows from the table the previous means, standard deviations, for respondents approval of grades on the 
items regarding the role of books and stories in the development of child's culture from the point of Jordanian mothers in descending order, where the item No. 11 got great grades of approval and a mean of (3.38), which states ( I give appropriate reinforcement for my child for his reading of books and educational stories) and the reason for this is may be due to providing support and permanent encouragement by some families for their children and urged them to read all kinds, this was clear in the study sample responses and their desire that their children become more knowledgeable and informed and more productive in their community and their contribution in its progress. The item which states that (develop his scientific knowledge and imagination) got the least mean (2.05). The reason may be due to the expectation of some of the families those books and stories contribute greately in the development of imagination and creativity but the reality was contrary to their expectations and their contribution was less than they expected. This is what was agreed with the study of (Ordiakik, and Rabouji 2006), which emphasized the role of the family in promoting knowledge, and the role of the family to develop reading and conversation through the participation of children in reading.

\subsection{Results for the Second Question}

Is there a statistically significant difference at the level of significance $(\alpha=0.05)$ in the role of mothers to the development of culture of the child, according to the variable of educational level of the mother?

To answer this question (Kruskal-Walls) test was used to know the significance of differences in the views of mothers about the role of religious institutions, electronic games, books and stories in the development of culture of the child depending on the level of education, the educational level of the mother was divided into three sections (secondary, moderate diploma, Bachelor degree and more) and the results were as follows:

Table 8. Kruskal Wales test results for the significance of differences in the views of mothers about the role of religious institutions, electronic games, books and stories in the development of the child's culture of the depending on the level of education

\begin{tabular}{|c|c|c|c|c|c|c|}
\hline Domains & Educational level & Number & Rank average & Chi square & Df & Sig \\
\hline \multirow{3}{*}{ Religious institutions } & 1 & 22 & 75.45 & 7.465 & 2 & 0.024 \\
\hline & 2 & 78 & 80.16 & & & \\
\hline & 3 & 75 & 99.83 & & & \\
\hline \multirow{3}{*}{ Electronic games } & 1 & 22 & 77.36 & 2.293 & 2 & 0.318 \\
\hline & 2 & 78 & 93.83 & & & \\
\hline & 3 & 75 & 85.05 & & & \\
\hline \multirow{3}{*}{ Books and educational stories } & 1 & 22 & 114.61 & 7.256 & 2 & 0.027 \\
\hline & 2 & 78 & 86.04 & & & \\
\hline & 3 & 75 & 82.23 & & & \\
\hline
\end{tabular}

Illustrated by reviewing the previous table (8) it is clear that there are and no statistically significant differences at the significance level (0.05) in the views of mothers in the role of religious institutions in the development of the culture of the child and it were in favor of level No. (1) Secondary stage. The reason may be due to that religious institutions are considered important educational institutions that teach positive values and promoting it in the minds of emerging and applied it on the ground and to consider religious values are the essence of human existence, which is directed and commandeered for many of the children's behavior based on even be good in themselves and their thoughts and feelings.

As regards the role of books and stories in the development of the culture of the child the difference was in favor of the educational level number (3) Bachelor degree or higher. The reason may be due to the confirmation of the high degrees owners of the great role played by books and educational stories in children's mental, cognitive and creative abilities and the development of his communication skills with others.

While their views were similar on the role of electronic games in the development of the child's culture no matter how the educational level of mothers. The reason for this discrepancy may be due to a variety of cognitive and mental levels and economic level of families if it is moderate or low it may justify the lack of importance of those games and consider it of the luxuries and not essential needs while the high income educational level insure the importance of those games in the mental and cognitive and cultural capacity development in a positive way. 


\subsection{Results for the Third Question}

Is there a statistically significant difference for the level of significance $(\alpha=0.05)$ in the role of religious institutions, electronic games, books and stories in the development of the culture of the child due to the economic level of the mother?

To answer this hypothesis (Kruskal-Walls) test has been used to know the significance of differences in the views of mothers about the role of religious institutions, games, e-books and stories in the development of the culture of the child depending on the economic level, and the results were as follows:

Table 9. Kruskal Wales test results for the significance of differences in the views of mothers about the role of religious institutions, electronic games, books and stories in the development of the child's culture depending on the economic level

\begin{tabular}{|c|c|c|c|c|c|c|}
\hline Domains & Economic level & Number & Rank level & Chi square & Df & Sig \\
\hline \multirow{3}{*}{ Religious institutions } & 1 & 72 & 82.35 & 1.606 & 2 & 0.448 \\
\hline & 2 & 100 & 91.76 & & & \\
\hline & 3 & 3 & 98.33 & & & \\
\hline \multirow{3}{*}{ Electronic games } & 1 & 72 & 90.28 & 0.336 & 2 & 0.845 \\
\hline & 2 & 100 & 86.65 & & & \\
\hline & 3 & 3 & 78.17 & & & \\
\hline \multirow{3}{*}{ Books and stories } & 1 & 72 & 83.02 & 1.670 & 2 & 0.434 \\
\hline & 2 & 100 & 90.89 & & & \\
\hline & 3 & 3 & 111.17 & & & \\
\hline
\end{tabular}

It is evident from Table 9 that there were no statistically significant differences at the significance level (0.05) in the views of mothers about the role of religious institutions or electronic games, books and stories in the development of child's culture attributed the economic level, this means that the similarity of their views on the role of religious institutions and electronic games, books and stories in the development of culture of the child no matter what the economic level is. Because children's culture a priority not related to the level of parents' income because parents with all classes are keen to meet what they see is important to their children as a priority and some cut part of their budget to provide those games, and the US report for Education (2009) pointed out the effect of high level income on the academic challenges positively because the academic study later is costly.

\subsection{Research Suggestions}

In light of the findings of the study the following are recommended:

1) The role of mothers is not only choosing educational games and stories and giving guidance but they should be guided to share their children in playing these games, and supply the library with research that confirms it.

2) Provide everything that would increase the child's cognitive, cultural and scientific growth whether stories or books or educational games contribute to the development of his mental and cognitive development, and study this this effect.

3) Build and cultivate a close relationship in the hearts of the children of the importance of the role of worship places for the dissemination of science, knowledge and education, which in turn contribute to the refinement of the child's personality and guide his behavior, supported by appropriate research.

\section{References}

Ahmed, S. (2014). Children's literature. Dar al maseera, Amman.

Asersa, S. (2007). The family and socialization, December article, Arab Children gate with the support of the Arab Gulf Program for Development (AGFUND).

Azzawi et al. (2014). Child's literature and culture. The House of Culture, Amman, Jordan.

Bakai, I. (2000). Children's libraries. Dar Aladdin, Damascus.

Cowan. R. (1999). Some Observations on School Community. Family Relations in School-in New found land.

Faisal, S. (1998). Children's literature and culture, a review reading. Publications of Arab Writers Union, 
Damascus.

Hiti, H. (1988). Child's Culture, the National Council for Culture and Arts, Kuwait.

ISESCO. (2006). Arab childhood problems and ways to face it from the Islamic perspective. Islamic Educational Scientific and Cultural Organization (ISESCO) publications.

Kanaan, Q. (2014). The cultural aspects of Islamic society study in cultural anthropology. Journal of the Faculty of Islamic Sciences, 8(15).

Mansour et al. (2009). Research Methods in education and psychology. Damascus University, Damascus.

Murtaza, S. (2008). The reality of the kindergarten libraries and the prospects for development. Damascus University Journal, 24(1).

Mutairi, M. (2010). The impact of the Arab media in the upbringing of the child and his relationship to the family. Kuwait University, working paper submitted to the family and the Arab media conference.

Qasim, A. (2010). The role of the family in child-rearing culturally. Retrieved from http://syria-news.com/readnews.php?sy_seq=116819

Rabije, M., \& Arditaceka. (2006). The Role of Parents in the Education of children. Journal of Education and practice, 22(17).

Salami, M. (2011). Contemporary methods for teaching child's literature. Dar Osama, Amman

Shehata, H. (2004). The Arab Children's Literature. Cairo, Egyptian Lebanese house

Soman et al. (2014). Children's literature and culture. Amman, the House of Culture

US Department of Education. (2009). Achievement gaps: How black and white students in public schools perform in mathematics and reading on the National Assessment of Educational Progress. Retrieved from http://nces.ed.gov/pubsearch/pubsinfo.asp?pubid=2011459

Usher, A., \& Kober, N. (2012). Student Motivation-An Overlooked Piece of School Reform Center on Education Policy. The George Washington University

Watfa, A. (2006). The Arab child culture at the time of challenges. World of Thought Journal, 34(3), $189-239$.

\section{Copyrights}

Copyright for this article is retained by the author(s), with first publication rights granted to the journal.

This is an open-access article distributed under the terms and conditions of the Creative Commons Attribution license (http://creativecommons.org/licenses/by/4.0/). 